\title{
Harlequin syndrome: the sudden onset of unilateral flushing and sweating
}

\author{
JAMES W LANCE, * PETER D DRUMMOND,* SIMON C GANDEVIA,* \\ JOHN G L MORRIS†
}

From the Departments of Neurology, Prince Henry Hospital, ${ }^{*}$ and Westmead Hospital, $\uparrow$ Sydney, Australia

SUMMARY Facial flushing and sweating were investigated in five patients who complained of the sudden onset of unilateral facial flushing in hot weather or when exercising vigorously. One patient probably suffered a brainstem infarct at the time that the unilateral flush was first noticed, and was left with a subtle Horner's syndrome on the side opposite to the flush. The other four had no other neurological symptoms and no ocular signs of Horner's syndrome. Thermal and emotional flushing and sweating were found to be impaired on the non-flushing side of the forehead in all five patients whereas gustatory sweating and flushing were increased on that side in four of the five patients, a combination of signs indicating a deficit of the second sympathetic neuron at the level of the third thoracic segment. CT and MRI of this area failed to disclose a structural lesion but latency from stimulation of the motor cortex and thoracic spinal cord to the third intercostal muscle was delayed on the non-flushing side in one patient. The complaint of unilateral flushing and sweating was abolished in one patient by ipsilateral stellate ganglionectomy. The unilateral facial flushing and sweating induced by heat in all five patients was thus a normal or excessive response by an intact sympathetic pathway, the other side failing to respond because of a sympathetic deficit. The onset in the four cases of peripheral origin followed strenuous exertion, which suggested that an anterior radicular artery may have become occluded at the third thoracic segment during torsion of the thoracic spine.

One of the most mysterious, dramatic and colourful of autonomic syndromes is the sudden appearance of flushing limited to one side of the face, a symptom that does not appear to have received attention in the past. The descriptive title of "harlequin syndrome" comes to mind although the analogy has been drawn previously by paediatricians who apply the term "harlequin colour change" to vasomotor instability in the newborn causing flushing of the dependent half of the body. ${ }^{1}$

Unilateral sweating in response to spicy foods, heat and exercise may develop spontaneously as "idiopathic hyperhidrosis" which is sometimes accompanied by flushing ${ }^{3}$ and sometimes not. ${ }^{45}$ Unilateral flushing as a primary complaint does not seem to have been previously recorded.

The stimulus for the present study was provided by

Address for reprint requests: Professor J W Lance, Department of Neurology, The Prince Henry Hospital, Little Bay 2036, NSW, Australia.

Received 19 June 1987 and in revised form 29 October 1987. Accepted 2 November 1987 five patients who observed asymmetry of facial flushing in hot weather or after exertion. Our investigations were planned to determine which side was at fault and to elucidate the mechanism of the syndrome.

\section{Case reports}

The main clinical characteristics are summarised in table 1 . Case 1 A woman aged 73 years first noticed asymmetry of flushing at the age of 64 after working hard in the garden on a hot day. When she looked in the mirror while washing her hands, she observed a distinct line of demarcation between the left half of her face which was red and the right half which retained its normal colour. There were no accompanying symptoms. Over the following 10 years she has often noticed the same phenomenon after exertion although the colour difference has become less marked over this time. She had not been aware of any change in sweating. There was no antecedent injury or illness of relevance. A fluctuating elevation of systolic blood pressure was first noted at the age of 68 years but no measurements had been recorded before then. On examination, the left pupil was slightly smaller than the right but there was no ptosis and the pupils reacted normally. The nervous and other systems 
Table 1 Summary of clinical characteristics, ocular signs and investigations. See also tables 2 and 3

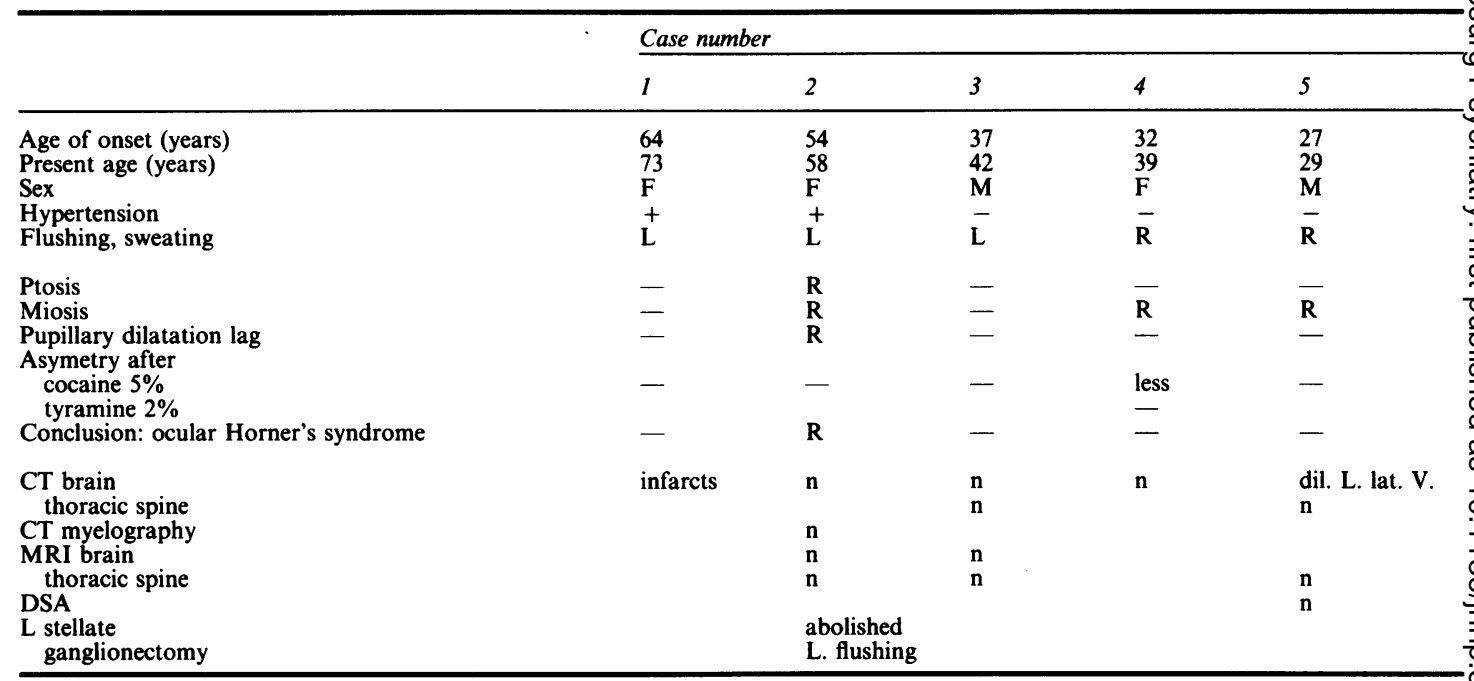

were otherwise normal apart from a blood pressure of 200/80 $\mathrm{mm} \mathrm{Hg}$.

Case 2 A woman aged 58 was walking in the sunlight with her daughter and grandchildren 4 years previously when she suddenly felt giddy "as though everything were turning around." She felt off balance and clutched a baby's pram for support. At the same time her daughter noticed that the left side of her face had become red and was sweating. Facial sweating subsided after 1 hour but her left facial flush persisted for 2 hours. Since that time any exertion such as housework or walking in hot weather has made the left side of her face and neck flush and sweat, a source of embarrassment that has caused her to stay at home most of the summer. She had not noticed redness or watering of her left eye or blockage of her left nostril. The rest of her body sweated normally. For the past year she had noticed transient weakness or "pins and needles" in her left arm and a burning sensation over the left side of her face and arm on occasions. Apart from a dull right frontal headache recurring intermittently since a car accident 22 years previously, she had experienced no other symptoms. There was a 30 year history of hypertension which had proved difficult to control. On the first examination, there was a slight right ptosis but her pupils were symmetrical and reacted normally to light and accommodation. Sensation to pinprick and temperature was diminished over the left half of her face and pharynx, with the deficit extending over the left arm and left upper quadrant of the trunk to below the nipple at the level of the sixth thoracic dermatome. There was slight weakness of finger flexors and small muscles of the hand on the left side and the left upper limb reflexes appeared to be less brisk than the right. Blood pressure was $160 / 110 \mathrm{~mm} \mathrm{Hg}$. On repeated examinations over the following year, her right pupil was noticed to be smaller than the left on occasions and the right ptosis was confirmed, the right palpebral fissure being 1.6 $\mathrm{mm}$ less than the left. The upper limb reflexes were then considered to be within the normal range of symmetry. The diagnosis was thought to be a right lateral medullary infarct but the possibility of syringomyelia could not be excluded on $\mathcal{G}^{\circ}$
clinical grounds. Case 3 A 42 year old man had been working hard laying 을 cables in his job as an electrician at the age of 37 when went to the changing room to wash and noticed that he wass $>$ flushed and sweating only on the left side of his foreheag. One week later after playing squash he saw that only the le $\overrightarrow{2}$ side of his face was flushed and sweating. This asymmeto had persisted for the past 5 years but sweating over the trun and limbs remained symmetrical. He flushes and sweats with embarrassment over the left side of the forehead only. For the past 5 years he had been subject to right retro-orbital headaches of mild to moderate severity, recurring up to four times each month, associated with nausea but these have $\stackrel{\circ}{\square}$ now subsided. His mother developed late onset diabetes. No $\cong$

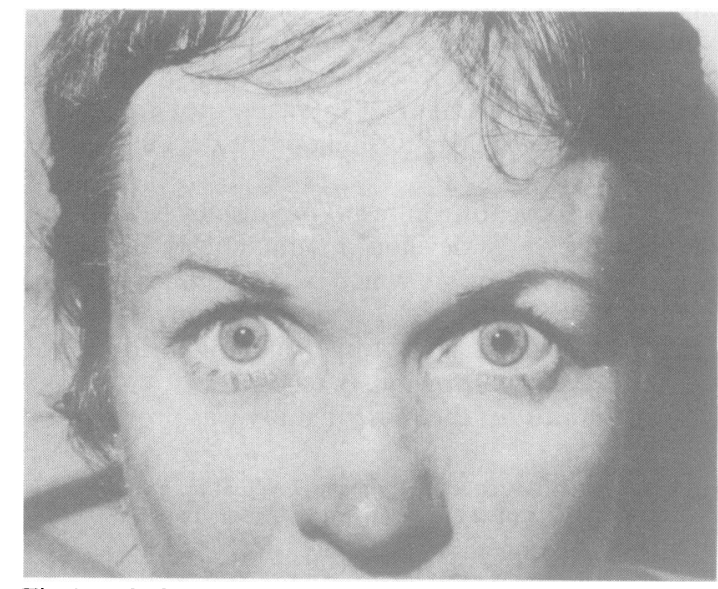

Fig 1 Flushing on the right side of the face after exertion (case 4). 
abnormality was found on full examination of the nervous and other systems. Blood pressure was $130 / 80 \mathrm{~mm} \mathrm{Hg}$.

Case 4 A woman aged 39 years, had finished playing a hard game of squash 7 years previously when a friend commented that the left side of her face remained pale and dry while the right side was flushing and sweating normally. Ever since, a sharp line of demarcation has appeared between the colour of each side of her face after 10 minutes of strenuous exertion (fig 1). She was not aware of any asymmetry of body sweating. At the time of onset of the symptom, she had just recovered from an infection of her left leg that had required treatment with antibiotics. Her mother had developed late-onset diabetes. On examination her right pupil was slightly smaller than the left but reacted normally. The nervous and other systems were otherwise normal. Blood pressure was $110 / 70 \mathrm{~mm} \mathrm{Hg}$.

Case 5 A 29 year old male landscape gardener had always sweated and flushed on both sides of his face until 2 years ago when his wife noticed that the right side of his forehead and upper face was a bright red colour after a game of squash, while the left side of his face appeared pale. This asymmetry persisted for about 20 minutes. Since that time he had flushed easily on exertion, or sometimes at rest on a hot day, with the flush involving chiefly the right side of the forehead, fading in intensity over the right side of the nose and the right cheek, sparing the chin and neck. At the same time, the right side of his face, particularly the forehead, sweated more than the left whereas sweating remained symmetrical over the remainder of his body. There were no other symptoms and no history of birth trauma or anything else of relevance in his past health or family history. On examination, his right pupil was smaller than the left but responded normally to light and accommodation. There was no ptosis. Subsequent testing revealed no evidence of a Horner's syndrome. No other abnormality was found on full examination of the nervous and other systems. His blood pressure was $120 / 80 \mathrm{~mm} \mathrm{Hg}$.

\section{Methods of investigation}

The experiments were carried out in an air-conditioned laboratory maintained at $22 \pm 1^{\circ} \mathrm{C}$. The subjects' informed consent to the procedures was obtained.

Facial flushing was measured thermographically and capillary pulsation was recorded by pulse transducers (photoplethysmographs, Narco Bio-Systems) attached with adhesive washers to the forehead and cheeks. ${ }^{6}$ The range of the AGA 680 Thermovision camera was $7^{\circ} \mathrm{C}$, and a heat source, set at $35^{\circ} \mathrm{C}$, was used for calibration. Change in amplitude of capillary pulsations was expressed as the percentage change from pretest level. ${ }^{6}$ Sweating on the upper and lower forehead was measured with an Evaporimeter EP1. Rate of evaporation was recorded in arbitrary units because calibration of the Evaporimeter was altered by placing a protective stainless steel grill over the measuring head. ${ }^{6}$

Pupil diameter was recorded on infrared film in a small light-tight photographic chamber. Photographs were taken at an illumination of 153.5 lux, and after 5 and 30 seconds of darkness $(0.04$ lux $)$ to investigate pupillary dilatation lag. Photographs were enlarged eight times so that diameter of the pupils and width of the palpebral fissures could be measured with calipers. A symmetrical response to the installa- tion in each eye of two drops of $5 \%$ cocaine (which blocks the reuptake of noradrenaline) was used to confirm the presence of normal sympathetic innervation of the pupil. On another occasion, eye drops of tyramine $2 \%$ (which releases noradrenaline from nerve terminals) were instilled to assess the presence or absence of neurotransmitter depletion.

Facial flushing and sweating was induced by body heating, embarrassment and the taste of chillies. The procedures have been described in detail elsewhere. ${ }^{6}$ Thermoregulation was tested by wrapping the patient in blankets and circulating hot air under the blankets until the patient sweated. Facial flushing after vigorous exercise (jogging around the hospital grounds and running up and down stairs) was measured thermographically in three patients. The other two patients, who were unable to exercise vigorously, were heated until they flushed and sweated. To induce embarrassment, a tape recording was made of the patient singing children's songs, and this was played back while measurements were carried out. Gustatory sweating and flushing was observed after tasting one-half teaspoon of Tabasco sauce. ${ }^{6}$

The integrity of the first, second and third thoracic motor roots was assessed in three patients by measurement of the latencies of contraction of the thenar and appropriate intercostal muscles respectively to stimulation of the motor cor-

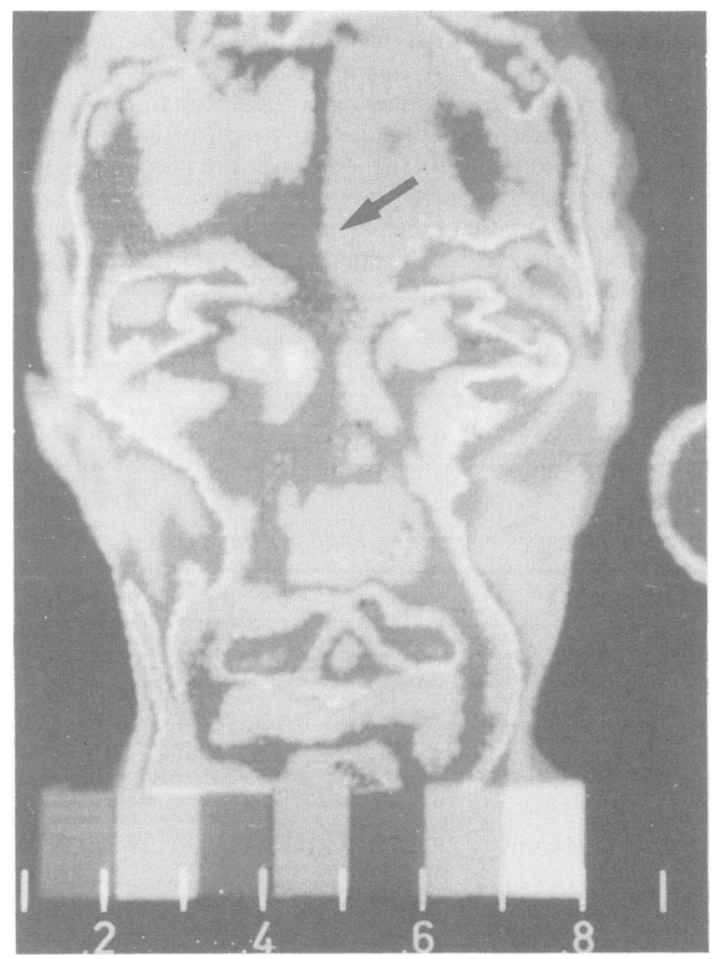

Fig 2 Thermogram after exertion in case 5. The right side of the forehead and right cheek increased in temperature by $2^{\circ} \mathrm{C}$, with a sharp line of demarcation from the left side becoming apparent (arrow). Temperature calibration (colour-coded in the original photograph) is at $1.0^{\circ} \mathrm{C}$ intervals. Temperature reference disc maintained at $35^{\circ} \mathrm{C}$. 
tex by the method of Merton and Morton ${ }^{7}$ and to stimulation over the vertebral column. ${ }^{8}$ Motor cortical stimuli were delivered using a Devices D180 stimulator with a maximal stimulus output of 750 volts (time constant $50 \mu \mathrm{s}$ ). Cup electrodes were fixed to the scalp with collodion at the vertex and six centimetres lateral to the vertex on both sides. Anodal stimuli were delivered to the lateral electrodes to activate the thenar muscles (cathode at vertex) and to the vertex to activate parasternal intercostal muscles (cathode positioned laterally, see Gandevia and Rothwell ${ }^{9}$ ). Cathodal stimuli were also delivered over the spinal cord at the C8/T1 and T2/T3 levels through surface electrodes with the anode positioned $6-8 \mathrm{~cm}$ cephalad. This form of stimulation activates the proximal region of the motor root. ${ }^{10}$

Electromyographic activity (EMG) was recorded from the thenar muscles with surface electrodes and from the second or third parasternal intercostal muscles with a pair of fine-wire electrodes (three $\mathrm{mm}$ of insulation removed). These electrodes were inserted $10-20 \mathrm{~mm}$ from the sternal edge via a single 25 gauge needle and activity was monitored during a variety of manoeuvres to ensure that they remained positioned within the intercostal muscles. Motor cortical stimuli were delivered during a weak voluntary contraction to ensure that minimal latencies were obtained. Spinal stimuli were delivered when the muscles were relaxed. Stimulus voltages were usually the same for recordings on both sides. Latencies were measured from a digital oscilloscope and where necessary up to eight responses were full-wave rectified and averaged following cortical stimuli.

The terms first, second and third sympathetic neuron are used simply to refer to the descending projection to the thoraco-lumbar outflows, the pre-ganglionic and postganglionic sympathetic neurons respectively. The terminology does not exclude the possibility of interneurons along sympathetic pathways.

\section{Results}

Pupillary responses

Pupillary dilatation lag was demonstrated on the right in case 2, thus confirming an ocular Horner's syndrome, but was not present in the other patients (table 1). In all cases pupils dilated normally in re- $\frac{c}{0}$ sponse to cocaine $5 \%$ eye drops although some aniso- 0 coria persisted in case 4 , pupillary diameters being 4.6 (

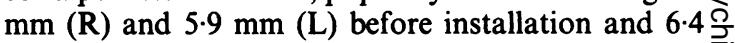
and $6.8 \mathrm{~mm}$ afterwards. Tyramine $2 \%$ drops were used only in case 4 without any asymmetry being. apparent, thus excluding a Horner's syndrome of $\vec{\Rightarrow}$ third neuron origin.

Brain and spinal cord imaging (table 1) Computed tomography (CT) of the brain was normal $\frac{\bar{p}}{\sigma}$ in cases 2-4. CT of case 1 showed multiple areas of $\stackrel{\mathbb{Q}}{2}$ low attenuation in the periventricular white matter, indicating demyelination, probably ischaemic in ori- $\vec{\circ}$ gin in view of the patient's age and systolic hypertension. In case 5, the temporal and occipital horns of $\vec{\omega}$ the left lateral ventricle were dilated without any mass? effect. The appearance was unchanged when the scan was repeated after 3 months and was considered to be of long-standing. CT of the thoracic spine, centred on the upper three thoracic segments, was normal in cases 3 and 5. CT myelography was normal in case 2 , $\mathrm{G}$ in whom syringomyelia had to be excluded. Magnetic $ᄋ$ resonance imaging (MRI) of the brain was normal in cases 2 and 3, and MRI of the cervical and thoractc 3 spinal cord in cases 2, 3 and 5 was also normal, es cluding syringomyelia. Digital subtraction angiography (DSA) in case 5 disclosed no abnormality the internal or external carotid circulations.

\section{Thermography}

After body heating, increased facial temperature was documented by infrared thermography in three cases. In case 2 , the left side of the face became warmer than $\mathbb{\mathbb { D }}$ the right by $1.5^{\circ} \mathrm{C}$ over the forehead and $1.0^{\circ} \mathrm{C}$ over $\underset{7}{\Rightarrow}$

Table 2 Studies of flushing and sweating

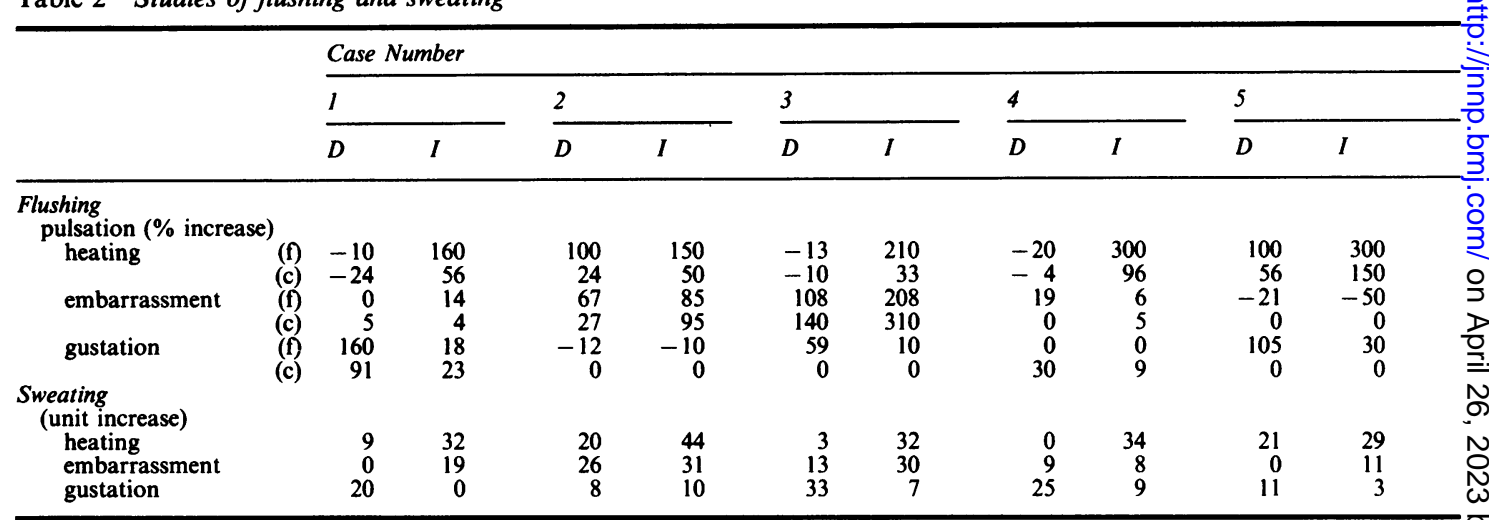

The symptomatic (flushing) side is designated as intact (I) and the non-flushing side as denervated (D). The denervated side flushes and sweats 2 less in response to heating and embarrassment but, with the exception of case 2 , responds more to gustatory stimuli. The results indicate that 0 the sympathetic lesion on the denervated side is of peripheral origin in cases $1,3,4$, and 5 .

(f): forehead; (c): cheek. 
the cheek. In case 3 , the left forehead and cheek became warmer than the right by $1.0^{\circ} \mathrm{C}$. In case 5 , the right forehead and cheek temperature increased by $2^{\circ} \mathrm{C}$ more than the left but heat loss from the chin remained symmetrical (fig 2 ).

\section{Capillary pulsations}

During the unilateral flush produced by body heating, the amplitude of capillary pulsations on the responsive side increased by $150-300 \%$ over the forehead and by $33-100 \%$ over the cheek while there was little or no increase on the opposite side (table 2). This indicated that sympathetic innervation was intact on the side that flushed in response to heating (designated $I$ in table 2) and impaired on the non-responsive denervated side (designated $\mathrm{D}$ in table 2 ) as described by Drummond and Lance. ${ }^{6}$

After embarrassment, asymmetry in pulsations was detected in only three of the patients. Pulsation was increased on the affected side of the forehead in case 1 , the cheek in case 2 and both areas in case 3 .

The change in capillary pulsation reversed sides after a gustatory stimulus in cases $1,3,4$ and 5 but no change was recorded in case 2 (table 2).

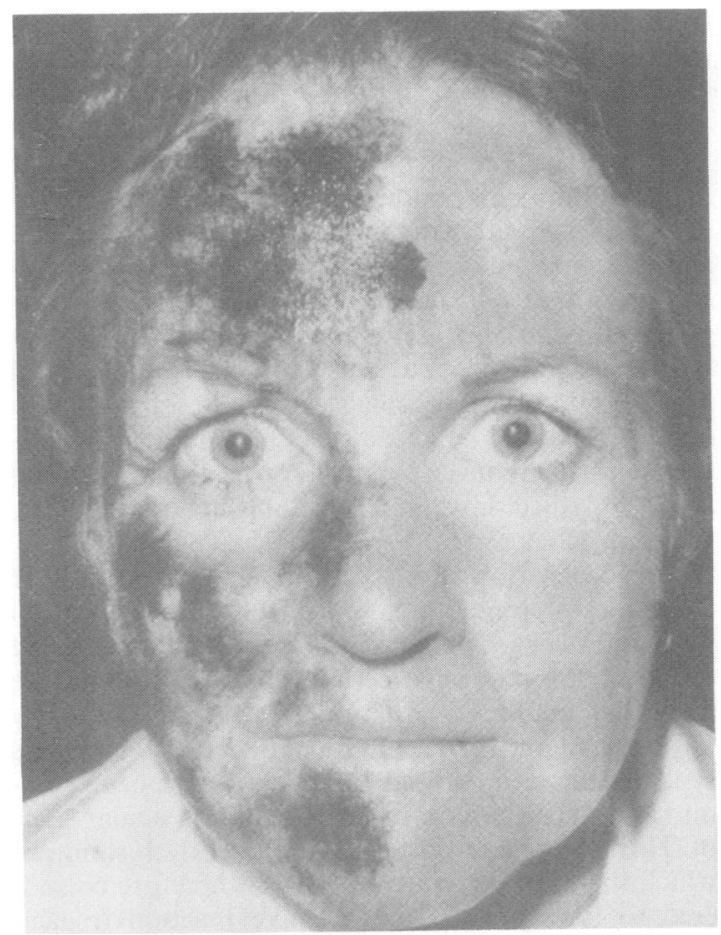

Fig 3 Sweating after exertion in case 4. The colour change of alizarin powder applied to the face demonstrates that the right side of the face sweats while the left remains dry.

\section{Sweating}

Sweating over the face was assessed qualitatively by the application of alizarin powder which changed colour when moist (fig 3) and quantitatively by measurement of evaporation from the forehead (table 2). Sweating was greater on the flushing side of the face in all cases in response to body heating. In four patients the asymmetry was apparent over forehead, cheek and, to a lesser extent in some, the chin (fig 3). In case 5, an area of anhidrosis on the non-flushing side was noted over the medial aspect of the forehead while sweating was only slightly diminished in other areas. Embarrassment caused increased sweating on the flushing side in cases 1,3 and 5 . The response to a gustatory stimulus was reversed in cases $1,3,4$ and 5 with excessive sweating on the non-flushing side that had sweated less during heating and embarrassment (table 2). These changes confirmed the presence of a

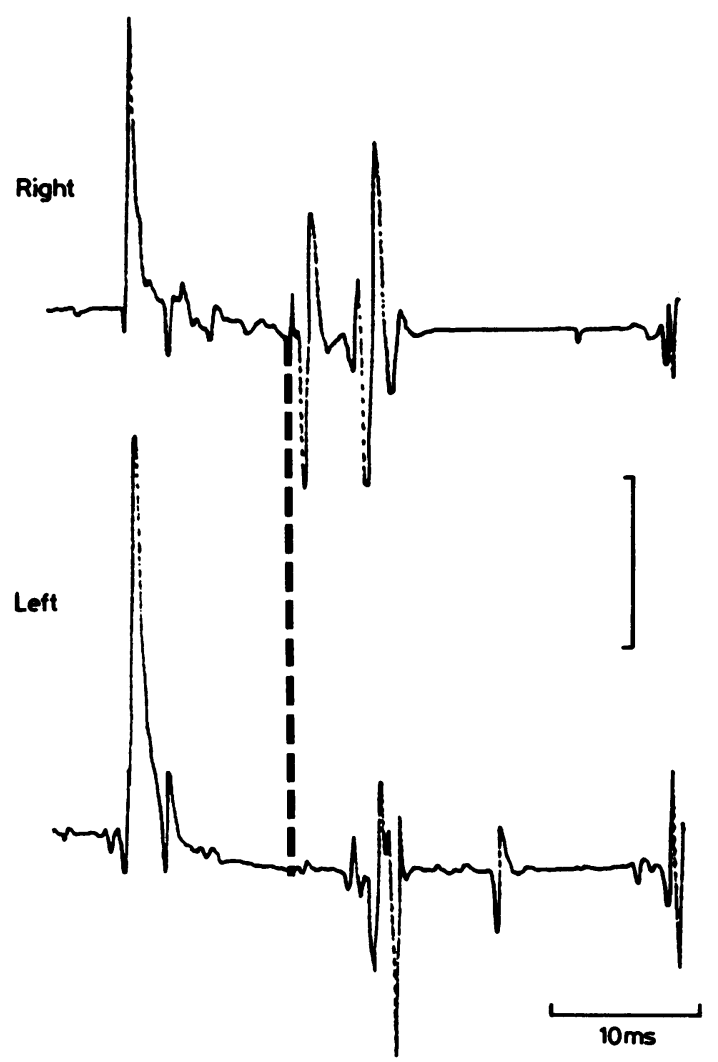

Fig 4 Typical electromyographic responses of the third intercostal muscles evoked by anodal stimulation of the motor cortex in case 5. The latency was increased by 3-4 ms on the left (non-flushing, non-sweating) side. Responses to spinal stimulation were similarly prolonged (table 3), indicating impaired conduction in the third thoracic motor root on the affected side. Vertical calibration: $200 \mu \mathrm{V}$. 
sympathetic lesion on the non-flushing side (D in table 2).

\section{Clinical neurophysiology}

Because the sympathetic outflow accompanying the second and third thoracic roots was of particular interest the latency of the second and third intercostal muscles to indirect stimulation of the motor cortex and to stimulation over the spinal cord was measured. In addition, the responses of the thenar muscles to spinal and cortical stimulation were assessed. Estimates of peripheral and central conduction times to thenar muscles were normal in the three patients studied (cases 3, 4, 5; see table 3). In case 5, the latencies to both cortical and spinal cord stimulation were prolonged to the third intercostal muscle on the nonflushing side, exceeding those on the other side by 3.4 and $4.2 \mathrm{~ms}$ respectively (fig 4 ). This patient showed a diminished interference pattern in the third interspace on the non-flushing side. Case 4 showed normal peripheral and central motor conduction to the third intercostal muscles and this was demonstrated for both second and third intercostal muscles in case 3 .

\section{Stellate ganglion block and ganglionectomy}

Because case 2 was of fair complexion and was troubled by the unsightly flushing of the left side of her face, her left stellate ganglion was blocked by lignocaine $2 \%$ with abolition of flushing and sweating on that side after body heating. The left stellate ganglion was therefore removed and she has not noticed any flushing or sweating on that side in the 18 months since operation. As she already had a partial ocular Horner's syndrome on the right side the left Horner's syndrome resulting from operation restored a pleasing symmetry.

\section{Blood glucose levels}

Fasting blood glucose levels were normal in all cases.

Table 3 Latency from stimulation of motor cortex and spinal cord to contraction of the thenar muscles and intercostal muscles in Cases 3, 4 and 5

\begin{tabular}{|c|c|c|c|c|c|}
\hline \multirow[b]{3}{*}{$\begin{array}{l}\text { latency (ms) } \\
\text { case } 3\end{array}$} & \multirow[b]{3}{*}{$\begin{array}{r}\mathrm{C} 8 / \mathrm{T} 1 \\
\mathrm{~T} 2 \\
\mathrm{~T} 3 \\
\mathrm{C} 8 / \mathrm{T} 1 \\
\mathrm{~T} 3 \\
\mathrm{C} 8 / \mathrm{T} 1 \\
\mathrm{~T} 3\end{array}$} & \multicolumn{4}{|c|}{ Site of stimulation } \\
\hline & & \multicolumn{2}{|c|}{ Motor cortex } & \multicolumn{2}{|c|}{ Spinal cord } \\
\hline & & $\begin{array}{r}\text { right } \\
22.6 \\
9.4 \\
11.5 \\
19.0 \\
11.5 \\
19.9 \\
11.5\end{array}$ & $\begin{array}{l}\text { left } \\
20.9 \\
8.7 \\
11.3 \\
19.1 \\
11.3 \\
19.3 \\
14.9^{*}\end{array}$ & $\begin{array}{r}\text { right } \\
16.9 \\
4 \cdot 6 \\
5.8 \\
14 \cdot 2 \\
4.4 \\
15 \cdot 0 \\
5 \cdot 1\end{array}$ & $\begin{array}{c}\text { left } \\
14.8 \\
4.6 \\
5 \cdot 3 \\
14.0 \\
5.0 \\
15.0 \\
9 \cdot 3^{*}\end{array}$ \\
\hline
\end{tabular}

Significant asymmetry was demonstrated in case 5 for stimulation at both motor cortical and spinal levels with the prolonged latencies $\left(^{*}\right)$ occurring on the non-flushing side.

\section{Discussion}

All five patients complained of the sudden onset of flushing and sweating on one side of the face, thus directing the attention of the clinician to this as the presumably abnormal side. On the initial examination of all five patients there was no ocular sign of Horner's syndrome. Anisocoria was observed in cases? 4 and 5 but there was no pupillary dilatation lag on exposure to darkness, indicating that sympathetic in- $\frac{\text { s }}{+}$ nervation of the iris was intact.

In contrast, repeated observation of case 2 dis- 믐 closed an inconstant miosis and ptosis on the right $\frac{\bar{\rho}}{\vec{D}}$ (non-flushing) side with pupillary dilatation lag on $\stackrel{\mathbb{Q}}{2}$ that side, thus demonstrating a mild right ocular Horner's syndrome. The normal response of the mi- $\vec{\theta}$ otic pupil to cocaine eye drops in this instance indicates that the lesion was central. ${ }^{11}$ This, together with $\vec{\omega}$ the abrupt onset of unilateral flushing accompanied $\stackrel{\text { ? }}{?}$ by vertigo in a hypertensive patient, suggested a brainstem infarction. The residual upper quadrantic ${ }^{\circ}$ impairment of sensation to pinprick and temperature would be consistent with this diagnosis although it ir was necessary to rule out the possibility of a syrinx by $\mathrm{G}$ CT myelography and MRI. The fact that this patient 0 failed to sweat and flush on the right side in response $?$ to heating but showed little asymmetry to embarrass $\vec{z}$ ment or gustatory stimuli indicates a lesion of the firg sympathetic neuron, a right central Horner's syr drome ${ }^{6}$ Because she had a fair skin that displayed hê: $\infty$ left sided flush readily, she confined herself to the house on hot summer days. It was therefore decided to remove her left stellate ganglion, a procedure that abolished her untoward reaction to body heating. It is of interest that Wilson ${ }^{2}$ described a patient with syringomyelia who did not show the ocular signs of $\mathbb{\perp}$ Horner's syndrome but was troubled by unilateral $\overrightarrow{\vec{A}}$ flushing and sweating which was relieved by ablation $\frac{9}{3}$ of the ipsilateral superior cervical ganglion. Gustatory sweating that develops after preganglionic cervical sympathectomy is also abolished by stellate ganglion block. ${ }^{12} 13$

The localisation of the site of the lesion in the other four cases presented greater difficulty. The failure to 3 flush and sweat in response to heat or embarrassment on the non-symptomatic (non-flushing) side of the face was quantitatively similar to that found by Drummond and Lance ${ }^{6}$ in 21 patients with Horner's syndrome and in two patients with lesions of the sec- $\frac{7}{0}$ ond and third thoracic roots who had no ocular signs of Horner's syndrome. The unilateral flushing of $N$ which the patients complained was therefore consid- $N$ ered to be a normal or excessive reaction to heat $\mathcal{N}$ which was conspicuous in relation to the lack of re- $\omega$ sponse on the contralateral side caused by sympathetic deficit. 
The enhancement of gustatory sweating and flushing on the side with reduced sympathetic activity in these four cases suggests that the lesion involves the second sympathetic neuron since this is a well recognised phenomenon developing after surgical sympathectomy, ${ }^{12-15}$ possibly caused by the sprouting of preganglionic sympathetic fibres originally destined for salivary glands. In contrast to the patients described here, cases of idiopathic hyperhidrosis sweat and flush on the affected side in response to both gustatory and thermoregulatory stimuli.

Impairment of sympathetic activity in one half of the face without ipsilateral ptosis and miosis implies a lesion at the level of the second or third thoracic segments of the spinal cord, in the intermediolateral cell column, root or white ramus. ${ }^{16}$ The third thoracic root probably carries the bulk of vasomotor and sudomotor fibres supplying the head and neck since sectioning the sympathetic trunk below the second thoracic sympathetic ganglion produces anhidrosis of the ipsilateral face and neck. ${ }^{17}$ Ocular sympathetic fibres most commonly leave the cord in the first thoracic root. Reactions of cases $1,3,4$ and 5 were similar to those of two patients after surgical resection of the second and third thoracic roots reported by Drummond and Lance. ${ }^{6}$ The greater impairment of sweating and flushing in the medial aspect of the forehead in case 5 resembled the deficit after a postganglionic lesion ${ }^{18}$ but the cheeks and chin were also involved in this patient to some extent. In spite of these localising signs, no lesion could be detected in the upper thoracic segment of the spinal cord or paravertebral area by CT or MRI. Latency of the second and third intercostal muscles to stimulation of motor cortex and spinal cord showed no asymmetry in cases 3 and 4 , but latencies to the third intercostal muscle indicated that motor fibres had been compromised in case 5 on the non-flushing side and thus supports the concept of an associated white ramus sympathetic lesion at that level.

The first and second pairs of intercostal arteries arise from the deep cervical arteries which are branches of the costocervical trunks. The third thoracic segment is supplied by an intercostal artery from the aorta in an area of the cord with poor collateral circulation. The segmental artery divides into an anterior and posterior ramus. A spinal artery leaves each posterior ramus and divides into a posterior and an anterior radicular artery which supply only the appropriate roots and do not contribute significantly to the spinal cord circulation. ${ }^{19}$ It is conceivable that an anterior radicular artery at the third thoracic segment could be occluded by torsion of the thoracic spine and thus give rise to the harlequin syndrome. It may be relevant that, of the four cases of peripheral origin described here, the onset was noted after a hard game of squash in two (cases 4 and 5), strenuous exertion laying cables (case 3 ) and working in the garden (case 1). Fasting blood sugar was normal in all cases so that diabetes was not a contributing factor.

It is not clear whether flushing and sweating was normal or excessive on the side with intact sympathetic innervation. In this context, it is of interest that Guttman ${ }^{20}$ reported hyperactivity of the sympathetic nervous system on the side of the face contralateral to cervical sympathectomy. The syndrome of unilateral flushing and sweating could therefore be exaggerated by a release phenomenon on the side opposite to that of the sympathetic deficit, which would compensate for loss of sweating and flushing on the denervated side and serve to maintain normal heat regulation.

In conclusion, five patients are presented with the sudden onset of unilateral flushing and sweating resulting from a contralateral sympathetic deficit. The site of the lesion in one instance (case 2) was almost certainly central but the evidence supports a peripheral lesion, affecting the sympathetic outflow through the third thoracic root, in the other four cases. The cause of such a selective radiculopathy remains unknown but a major structural lesion has been excluded with reasonable certainty. The most likely explanation is occlusion of an anterior radicular artery during strenuous exertion.

The authors thank those who referred patients for this investigation: Dr G Phipps (case 1); Dr GT Bassil (case 2); Dr R Joffe (case 3); Dr FS Lance (case 4) and Dr JG Polgar (case 5), and to the patients for their cheerful submission to these investigations. The figures were prepared by the Department of Medical Illustration, University of New South Wales. We are grateful to the National Health and Medical Research Council of Australia, the Adolph Basser Trust, the JA Perini Family Trust and Mr and Mrs Warren Anderson for their support. Richardson-Vicks Pty Ltd kindly made the Evaporimeter available to us for these investigations.

\section{References}

1 Esterly NB, Spraker MK. Neonatal skin problems. In: Dermatology. Vol. 2. Ed. Moschella SL, Hurley HJ. Philadelphia, Saunders, 1985:1882.

2 Wilson WC. Observations relating to the innervation of the sweat glands of the face. Clin Sci 1936;2;273-286.

3 Pearce JMS. Abnormal facial sweating. Br J Clin Pract 1964;18:409-12.

4 Tankel HI. A case of gustatory sweating. J Neurol Neurosurg Psychiatry 1951;14:129-33.

5 Shafar J. The syndromes of the third neurone of the cervical sympathetic system. Am J Med 1966;40:97-109.

6 Drummond PD, Lance JW. Facial flushing and sweating 
mediated by the sympathetic nervous system. Brain 1987;110:793-803.

7 Merton PA, Morton HB. Stimulation of the cerebral cortex in the intact human subject. Nature 1980; 285:227.

8 Mills KR, Murray NMF. Corticospinal tract conduction time in multiple sclerosis. Ann Neurol 1985;18:601-5.

9 Gandevia SC, Rothwell JC. Activation of the human diaphragm from the motor cortex. $J$ Physiol (Lond) 1987;384:109-18.

10 Mills KR, Murray NMF. Electrical stimulation over the human vertebral column. Which neural elements are excited? Electroencephalogr Clin Neurophysiol 1986; 63:582-9.

11 Jaffe NS. Localization of lesions causing Horner's syndrome. Arch Ophthalmol 1950;44:710-28.

12 Haxton HA. Gustatory sweating. Brain 1948;71:16-25.

13 Ashby WB. Gustatory sweating and pilomotor changes. Br J Surg 1960;47:406-10.

14 Herxheimer A. Gustatory sweating and pilomotion. $\mathrm{Br}$
Med J 1958;1:688-9.

15 Bloor K. Gustatory sweating and other responses after cervico-thoracic sympathectomy. Brain 1969;92: 137-46.

16 Goetz RH. The surgical physiology of the sympathetic $\square$ nervous system with special reference to cardiovascular disorders. Int Abstr Surg 1948;87:417-39.

17 Schliack H. Segmental innervation and the clinical aspects of spinal nerve root syndromes. In: Handbook of Clinical Neurology, Vol 2., Vinken PJ, Bruyn GW, eds. Amsterdam: North-Holland, 1969:157-77.

18 Morris JGL, Lee J, Lim CL. Facial sweating in Horner's syndrome. Brain 1984;107:751-8.

19 Herrick MK, Mills PE Jnr. Infarction of spinal cord. Two cases of selective gray matter involvement secondary to asymptomatic aortic disease. Arch Neurol $\unrhd$ 1971;24:228-41.

20 Guttmann L. The distribution of disturbances of sweat secretion after extirpation of certain sympathetic cervical ganglia in man. $J$ Anat 1940;74:537-49. 